\title{
Correction to: Assessment of rainwater harvesting sites in a part of North-West Delhi, India using geomatic tools
}

\author{
Sandhya Farswan ${ }^{1} \cdot$ Chandrashekhar Azad Vishwakarma ${ }^{1} \cdot$ Usha Mina $^{1} \cdot$ Vijay Kumar $^{1} \cdot$ Saumitra Mukherjee $^{1}$ (D)
}

Published online: 4 September 2020

c) Springer-Verlag GmbH Germany, part of Springer Nature 2020

Correction to: Environ Earth Sci

https://doi.org/10.1007/s12665-019-8332-y

The original article has been published inadvertently with some errors in Table 6-the last sentence of the abstract and the last sentence after Eq. (2) $(581 \mathrm{~mm})$. The corrected Table 6 is given below."

\begin{abstract}
The study was conducted with an aim to provide practical solution for the groundwater management in three villages namely Singhola, Ghoga and Dhirpur of the North-West Delhi, India. LANDSAT remote-sensing datasets for the last four decades (1977-2018) were assessed to determine changes in vegetation cover at the selected sites. The Google Earth Engine was used to determine how values of the Normalized Difference Vegetation Index (NDVI) were found to have varied spatially and over time for the selected sites. Strong correlations were found between the NDVI values of
\end{abstract}

surface features including waterbodies, forest land, agricultural land and urban areas in Singhola, Ghoga and Dhirpur, respectively. The relative infiltration capacity of soils was highest (92.9\%) and lowest (57\%) for Singhola and Dhirpur, respectively, due to spatial differences in soil texture. In each village, locations exhibiting a higher soil infiltration capacity could be used for implementing managed aquifer recharge schemes using rainwater harvested from rooftops in the villages. This assessment indicated that the village of Ghoga has the highest potential $\left(37,698.01 \mathrm{~m}^{3}\right)$ for aquifer recharge through rooftop rainwater harvesting as compared to the other two villages.

Rooftop capacity $=$ Rooftop area $\mathrm{m}^{2}$

$$
\begin{aligned}
& \times \text { average annual monsoon rainfall } \\
& \times 0.8
\end{aligned}
$$

where average annual monsoon rainfall for North-West Delhi is $581 \mathrm{~mm}$ and 0.8 is runoff coefficient (CGWB 2016).

The original article can be found online at https://doi.org/10.1007/ s12665-019-8332-y.

Saumitra Mukherjee

saumitramukherjee3@gmail.com

1 School of Environmental Sciences, Jawaharlal Nehru

University, New Delhi 110067, India 
Table 6 Rooftop rainwater harvesting potential of the sites

\begin{tabular}{llllll}
\hline S. no & Site name & $\begin{array}{l}\text { No. of roofs } \\
\text { measured }\end{array}$ & Rooftop area $\left(\mathrm{m}^{2}\right)$ & $\begin{array}{l}\text { Rooftop } \\
\text { perimeter }(\mathrm{m})\end{array}$ & $\begin{array}{l}\text { Rain water catchment } \\
\text { potential of rooftop } \\
\left(\mathrm{m}^{3}\right)\end{array}$ \\
\hline 1 & Singhola & 453 & $68,632.76$ & $21,429.26$ & $31,900.50$ \\
2 & Ghoga & 916 & $81,105.88$ & $36,157.93$ & $37,698.01$ \\
3 & Dhirpur & 514 & $47,820.07$ & $19,784.72$ & $22,226.77$ \\
\hline
\end{tabular}

Publisher's Note Springer Nature remains neutral with regard to jurisdictional claims in published maps and institutional affiliations. 